\title{
Influence of Ag Micro-addition on the Bending Fracture Behavior of Cu-Based Metallic Glasses
}

\author{
Ling ZHANG ${ }^{a^{*}}$, Xiang-Bin $\mathrm{YI}^{\mathrm{b}}$, Wen-Chun $\mathrm{CHANG}^{\mathrm{c}}$, Jian-Chen SHENG \\ Lanzhou Institute of Technology, Lanzhou 730050, China \\ a596760816@qq.com, ${ }^{b} 530064133 @ q q . c o m,{ }^{c} 380455274 @ q q . c o m,{ }^{d} 155230180 @$ qq.com \\ ${ }^{*}$ Corresponding author
}

\begin{abstract}
Keywords: Cu-based Bulk Glass, Glass Forming Ability, Thermal Stability, Compression Performance, Fracture Morphology.
\end{abstract}

\begin{abstract}
In order to improve the glass forming ability of $\mathrm{Cu}$-based bulk amorphous, improve it's mechanical properties and plasticity, the $\mathrm{Cu}_{46} \mathrm{Zr}_{42} \mathrm{Al} \mathrm{Ag}_{4}$ alloy rods with $3.0 \mathrm{~mm}$ in diameter were prepared by the suspend melting-copper mold suction casting. The structure, thermal stability and flexural behavior were tested. The results showed that the structure of all rod was composed of amorphous phase. The addition of Ag improve the bending strength of copper base block amorphous. The bending strength of without adding Ag element is $2717.57 \mathrm{Mpa}$ up to 2995Mpa. Fracture presents the venation of long and narrow uplift, local plastic deformation occurred.
\end{abstract}

\section{Introduction}

Block amorphous alloy has high strength, hardness, toughness, wear resistance, corrosion resistance and excellent characteristics of soft magnetism, superconductivity, pay special attention to by material science and industry. But because most of the amorphous alloy lacks obvious plastic deformation ability, which limiting its extensive usage as the wide use of high strength structural materials. In order to improve the mechanical properties of bulk amorphous alloy, especially room temperature plasticity, material workers to explore the room temperature plasticity of bulk amorphous alloy system. for example, the Pt-base bulk metallic glass was prepared by Johnson [1] which up to $3 \mathrm{~mm}$ in diameter, compression plasticity can be up to $20 \%$, and breaks through bottleneck that the amorphous alloy compression is less than 2\% ; The Pd - Si dual bulk amorphous alloy which Yao Ke-fu [2] reported and the $\mathrm{Zr}-\mathrm{Cu}-\mathrm{Ni}-\mathrm{Al}$ block amorphous alloy that Wang Wei-hua [3] found all have the high strength and high plasticity. During the study found that amorphous alloy at room temperature is highly uniform deformation, deformation is confined to the narrow shear zone area [4-7].For now, however, the formation and expansion mechanism of shear zone and the relationship with the macroscopic properties of the $[8,9]$ have not yet fully elucidated the fracture mechanism of amorphous.On the other hand, micro alloying is one of the effective ways to improve the performance of BMG, doping elements to improve the system of different atomic size, effectively improve the ability of the amorphous alloy formation and mechanical properties of [10].In this paper, choose for $\mathrm{Cu}-\mathrm{Zr}$ - $\mathrm{Al}$ substrate, using the traditional copper casting method, by adding the appropriate composition of optimization and alloying elements to increase mechanical properties of the alloy, hope to get the latest research achievements of $\mathrm{Cu}$ base bulk amorphous alloy for other bulk amorphous alloy research and the analysis is of great significance.

\section{Experiment}

Alloy ingots with nominal composition of $\mathrm{Cu}_{46} \mathrm{Zr}_{42} \mathrm{Al}_{8} \mathrm{Ag}_{4}$ were prepared by levitation melting of pure $\mathrm{Cu}, \mathrm{Zr}, \mathrm{Al}$ and $\mathrm{Ag}$ metals (purity $\geq 99.99 \%$ ). Sample rods with a diameter of $4 \mathrm{~mm}$ and a length of $75 \mathrm{~mm}$ were prepared by copper mold suction casting from the master ingot under Ar atmosphere. The structures of the samples obtained were examined by X-ray diffraction (D/max-2400). The thermal response of samples was investigated with differential scanning calorimetry (DSC) at a heating rate of $20 \mathrm{~K} / \mathrm{min}$ under a constant flow of argon.

The three-point bending strength was investigated by universal mechanical testing machine 
(SHIMADZU AG-10TA). The morphology of fractured samples and the lateral surface after fracture were examined with JSM-6700F, a scanning electron microscope (SEM).

\section{Results and Discussion}

\section{The Effect of the Addition of Ag on the GFA and Thermal Stability}

Fig. 1 shows the X-ray diffraction (XRD) spectra of at cast $\mathrm{Cu}$-based alloys with different content of $\mathrm{Ag}$. From the Fig. 1 we can see that the alloys with 0 , 4at\% $\mathrm{Ag}$ are typical amorphous, as indicated by a broad typical diffraction bump $\left(2 \theta=38^{\circ}\right)$ with the absence of any detectable crystalline peaks.

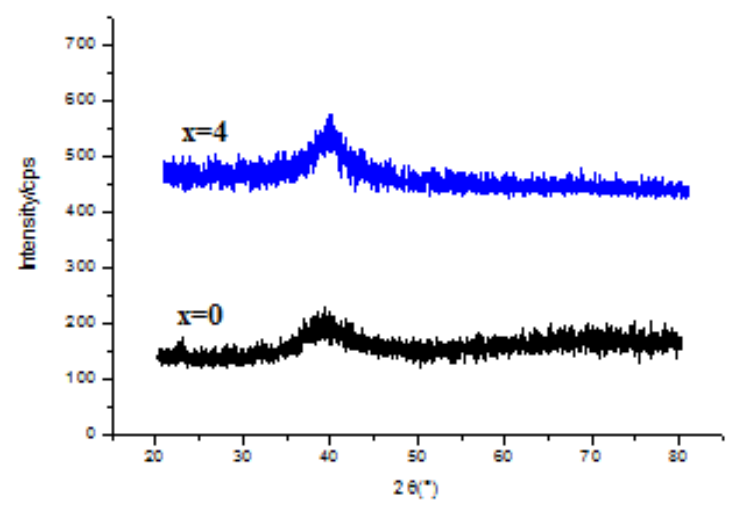

Fig. 1 XRD patterns of $\mathrm{Cu}_{50-\mathrm{x}} \mathrm{Zr}_{42} \mathrm{Al}_{8} \mathrm{Ag}_{\mathrm{x}}(\mathrm{x}=0$, 4)metallic glass

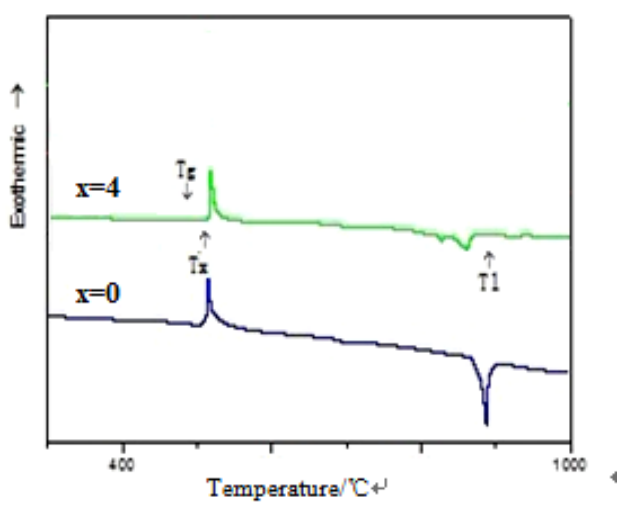

Fig.2 DSC curves of as-cast $\mathrm{Cu} 50-\mathrm{xZr} 42 \operatorname{Al} 8 \operatorname{Agx}(\mathrm{x}=0,4)$

Fig. 2 shows the DSC curves of Cu 50-xZr42Al8Agx $(x=0,4)$ alloys. They all exhibited a distinct glass transition and wide supercooled liquid region before crystallization. The onset temperature for glass transition $\mathrm{Tg}$ and the first crystallization $\mathrm{Tx}$, supercooled liquid region $\Delta \mathrm{Tx}(=\mathrm{Tx}-\mathrm{Tg})$ and glass transition temperature $\operatorname{Trg}(=\mathrm{Tg} / \mathrm{T} 1)$ are listed in Table 1.

We can see that, with the addition of Ag content, $\Delta \mathrm{Tx}$ increases slightly. At the same time, Trg from 0.618 for Ag-free alloy increased to 0.633 for containing 4 at\% $\mathrm{Ag}$. It is noted that the addition of $\mathrm{Ag}$ is beneficial to the formation of amorphous and to improve the thermal stability of the alloy.

Tab. 1 Values obtained from DSC of amorphous alloys $\mathrm{Cu}_{50-\mathrm{x}} \mathrm{Zr}_{42} \mathrm{Al}_{8} \mathrm{Ag}_{\mathrm{x}}(\mathrm{x}=0,4)$

\begin{tabular}{cccccc}
\hline & $T_{\mathrm{g}}(\mathrm{k})$ & $T_{\mathrm{x}}(\mathrm{k})$ & $T_{1}(\mathrm{k})$ & $\Delta T_{\mathrm{x}}(\mathrm{k})$ & $T_{\mathrm{rg}}(\mathrm{k})$ \\
\hline $\mathrm{x}=0$ & 725 & 784 & 1173 & 59 & 0.618 \\
$\mathrm{x}=4$ & 720 & 780 & 1138 & 60 & 0.633 \\
\hline
\end{tabular}

\section{The Test Results of Bending Performance}

Amorphous alloy $\mathrm{Cu} 46 \mathrm{Zr} 42 \mathrm{Al} 8 \mathrm{Ag} 4$ rod displacement load curve as shown in fig.3.

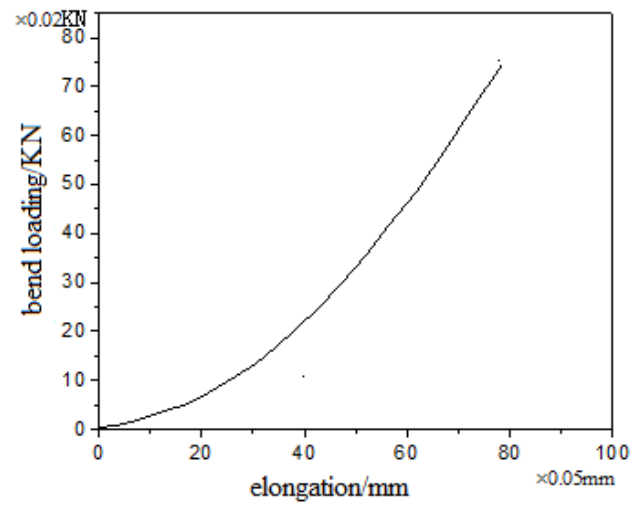

Fig.3 Load-displacement curve of $\mathrm{Cu}_{46} \mathrm{Zr}_{42} \mathrm{Al}_{8} \mathrm{Ag}_{4} \mathrm{BMG}$ alloy 
Fig. 3 shows the sample in the process of bending, elongation and bending load has a good linear relationship, no plastic deformation stage, as a typical brittle fracture.The bending strength of Sample was calculated by the following formula (1).

$$
\delta_{b b}=\frac{F_{b b} \times L_{s}}{4 W}
$$

Type of $F_{\mathrm{bb}}$ for maximum load (N); Ls to span (mm); W for bending section coefficient $\left(\mathrm{mm}^{2}\right)$.

The experimental testing results and datas according to the formula (1) listed in table 2.

Tab. 2 Bending experimental findings of Cu46Zr42Al8Ag4 BMG alloy

\begin{tabular}{ccccc}
\hline Alloy composition & $\begin{array}{c}\text { Bending deflection } \\
(\mathrm{mm})\end{array}$ & $\begin{array}{c}\text { Span } \\
(\mathrm{mm})\end{array}$ & $\begin{array}{c}\text { Bending load } \\
(\mathrm{KN})\end{array}$ & $\begin{array}{c}\text { Bending strength } \\
(\mathrm{Mpa})\end{array}$ \\
\hline $\mathrm{Cu}_{46} \mathrm{Zr}_{42} \mathrm{Al}_{8} \mathrm{Ag}_{4}$ & 3.75 & 50 & 15.05 & 2998 \\
\hline
\end{tabular}

Can be seen from table 2, the rod of amorphous and gold $\mathrm{Cu}_{46} \mathrm{Zr}_{42} \mathrm{Al}_{8} \mathrm{Ag}_{4}$ bending strength of 2998 Mpa, which slightly bigger than $\mathrm{Cu}_{47} \mathrm{Zr}_{42} \mathrm{Al}_{8} 2717.57$ the bending strength .Knowable in $\mathrm{CuZrAl}$ adding the right amount of $\mathrm{Ag}$ series of amorphous alloy can improve the mechanical properties of the amorphous and improve the bending strength.

\section{Fracture Surface Observation}

Fig.4 shows the fracture topography of amorphous alloy $\mathrm{Cu}_{46} \mathrm{Zr}_{42} \mathrm{Al}_{8} \mathrm{Ag}_{4}$ rod.
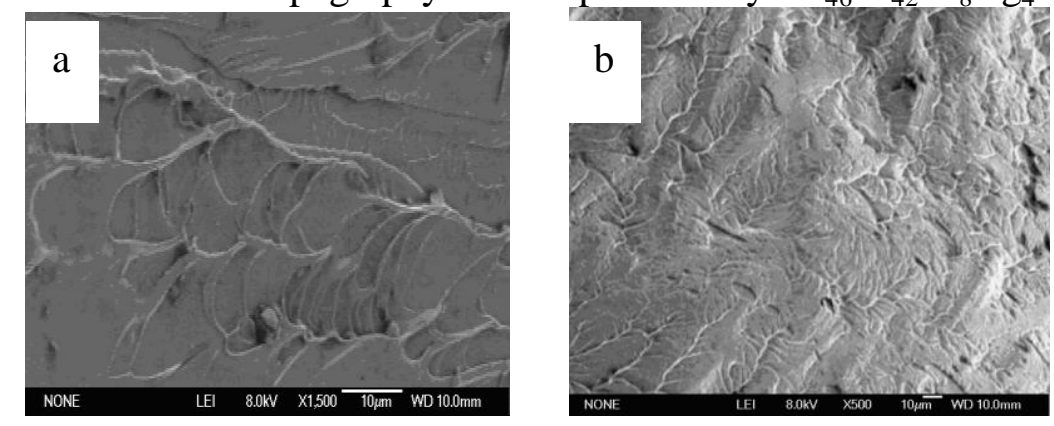

Fig. 4 Flexural fractography of $\mathrm{Cu}_{46} \mathrm{Zr}_{42} \mathrm{Al}_{8} \mathrm{Ag}_{4} \mathrm{BMG}$ alloy

In bending experiments, shear zone and the crankshaft in parallel. Through the sample on the fracture morphology of present a clear venation pattern, the sample is warped at room temperature shows that the local plastic deformation. In addition to form the context of the long and nearer between two solid surfaces.(slip band) is due to the formation of liquid layer caused by shear stress in the process of bending the result of "free volume increased". By the experimental results indicate that in $\mathrm{CuZrAl} \mathrm{block}$ amorphous alloy add Ag alloy elements can improve the bending strength of copper base block amorphous, and the microstructure characteristics are closely related. Amorphous materials exist chemical model and topology morow uplift, fracture surface is flat. Form the fault pattern is due to the result of the fracture fluid and two kinds of short-range order, different size mismatch between atoms and big negative heat of mixing For CuZrAl block amorphous alloy, after the transition metal Ag replaced part of $\mathrm{Cu}$, found that the atomic radius is large, increase the mismatch between the atoms, makes the different radius of the atom in the largest extent, closely arranged, ingredient in the alloy is not easy to produce long-range diffusion, reduced the number of alloy internal free volume, thus improves the bending strength of $\mathrm{Cu}$ base amorphous. Another reason of improve the bending strength can be regarded as amorphous alloy in rapid solidification effect in the process of forming, in the process of solidification due to the direct contact with the liquid alloy and copper wall, sample which is formed by the center and surface cooling speed which can lead to different residual stresses are present in the forming of amorphous alloy, thus improves the bending strength of specimens.

\section{Summary}

$\mathrm{Cu}_{46} \mathrm{Zr}_{42} \mathrm{Al}_{8} \mathrm{Ag}_{4} \mathrm{BMG}$ were prepared by copper mold suction casting with a diameter of $4 \mathrm{~mm}$ and a 
length of $7 \mathrm{~mm} ; \Delta T_{\mathrm{x}}$ and $T_{\mathrm{rg}}$ have certain enhancement, indicating that the addition of $\mathrm{Ag}$ improve amorphous glass formation ability and thermal stability; In addition, Through the amorphous alloy $\mathrm{Cu}_{46} \mathrm{Zr}_{42} \mathrm{Al}_{8} \mathrm{Ag}_{4}$ for three point bending damage experiment and observation of fracture morphology indicated that $\mathrm{Ag}$ alloy elements added to improve the bending strength of copper base block amorphous. Fractures in addition to form the context of the long and narrow uplift, fracture surface is flat, which illustrate that the local plastic deformation, deformation mechanism can be made of "free volume" model theory to explain.

\section{Acknowledgement}

About the author: Ling Zhang(1980-),Female,Lecturer,Master,Mainly engaged in the preparation and properties of amorphous. Email:596760816@qq.com.

Foundation item: Funded projects in Gansu Province Department of Education(2015A-164); Youth science and technology innovation project of Lanzhou Institute of Technology(15k-003).

\section{References}

[1] J. Schroers, W. L. Johnson, Ductile bulk metallic glass [J]. Physical Review Letters,2004, 93(25): 255506(4).

[2] K. F. Yao, F. Ruan, Y. Q. Yang, and N. Chen, Super ductile bulk metallic glass [J]. Applied Physics Letters, 2006, 88:122106(3).

[3] Y. H. Liu, G. Wang, R.J. Wang, D. Q. Zhao, M. X. Pan, W. H. Wang, Super plastic bulk metallic glasses at room temperature [J]. Science, 2007, 315:1385-1388.

[4] Liu C T, Heatherly L, Easton D S, Carmichael C A, Schneibel J H, Chen C H, Wright J L, Yoo M H, Horton J A, Inoue A. Metall Mater Trans, 1998,29A:1811.

[5] Bruck H A, Rosakis A J, Johnson W L. J Mater Res, 1996:11-503.

[6] Wright W L, Saha R, Nix W D. Metall Mater Trans, 2001: 42-642.

[7] Zhang Q S, Zhang H F, Wang A M, Ding B Z, Hu Z Q. Acta Metall Sin,2002:38-835(in Chinese).

[8] Petrovic V S, Xydeas C S. Objective image fusion performance measure electro[J]. Lett 2000, 36(4):308 -309.

[9] Li Shutao, Wang Yaonan, The muti-sensor image fusion based t millimeter wave, 2001, 20(3):119-222(in Chinese).

[10] Sun Jun,Zhang Guojun, Liu Gang.The research progress of bulk amorphous alloy mechanical.properties [J].Xi an Jiaotong University,2001, 35(6):640-645.(in Chinese). 